\title{
Clinical Trial Member Detail Documentation
}

National Cancer Institute

\section{Source}

National Cancer Institute. Clinical Trial Member Detail Documentation. NCI Thesaurus.

Code C115659.

Records that detail the roles of trial members, their contact details, and the structure of the team of a clinical trial. 